\title{
Validating the Measuring Instrument for Motivation Factors towards Visiting Spa and Wellness Tourism Destinations in Kuala Lumpur
}

\author{
Nik Alif Amri Nik Hashim, Sathish Kumar Velayuthan, Abdullah Muhamed Yusoff, Zaimatul \\ Awang, Fauzan Hafiz Muhammad Safri
}

\begin{abstract}
Visiting Spa and wellness tourism destinations is a new social trend among wellness tourist around Malaysia as this industry is still at a growth stage in the product lifecycle. However, limited interest has been paid on the study of domestic tourist motivation to visit the spa and wellness tourism destination. Thus, by applying the quantitative approach, the purpose of this pilot study is to assess the validity and reliability of the instrument used in measuring the motivation factors towards visiting spa and wellness tourism destinations in Kuala Lumpur. A total of 150-sample data were analysed using the statistical software IBM SPSS version 23. Before that, content and face validity, reliability and data normality were examined based on expert assessment. The result of the pilot study indicated that the measuring instruments used in this study are reliable, and the data is proved of rational normality. The findings of this study provided overall support for the proposed measuring instrument for further research.
\end{abstract}

Index Terms: Motivation, Visit, Spa, Wellness, Domestic Tourist

\section{INTRODUCTION}

Recently, the reality shows that the numbers of the spa centre and wellness targeted on raising and practice towards a more beneficial way of life. Individual health and wellness concern is one of the central points that contribute to the triumph of this industry. These can be seen from the action by the global spa industry, which actively promotes the spa industry to the next level of the relentless world with new eras of provident and more advantageous people groups. Global Spa and Wellness Summit (GSWS) has been administrating the global spa industry to improve the quality of services that involve all level of stakeholders both regional and global by discussing

Revised Manuscript Received on June 16, 2019.

Nik Alif Amri Nik Hashim, Faculty of Hospitality, Tourism \& Wellness, Universiti Malaysia Kelantan, Malaysia.

Sathish Kumar Velayuthan, Faculty of Hospitality, Tourism \& Wellness, Universiti Malaysia Kelantan, Malaysia.

Abdullah Muhamed Yusoff, Faculty of Hospitality, Tourism \& Wellness, Universiti Malaysia Kelantan, Malaysia.

Zaimatul Awang, Faculty of Hospitality, Tourism \& Wellness, Universiti Malaysia Kelantan, Malaysia.

Fauzan Hafiz Muhammad Safri, Faculty of Hospitality, Tourism \& Wellness, Universiti Malaysia Kelantan, Malaysia. the contemporary patterns and issues identified with this industry [4].

In Malaysia, it cannot deny the fact that Malaysian Spa and Wellness industry has the most significant potential to become one of the best contributing industries to Malaysian Economic and Tourism industry [5]. In recent years, Malaysia is well-known for the development of health tourism due to its traditional therapies that are the oldest treatments in the world [9]. The attractive medical tourism packages have made Malaysia is one of the competitive spa and wellness tourism destinations in Asia. Spas are places to offer expert services which help to enhance people's well-being through refreshing mind, body and spirit [7]. Now it has turned into a familiar pattern between Malaysian urban vacationers to visit spa and wellness centres to rejuvenate themselves, and such succession is a vow by Malaysian Association of Wellness and Spa (MAWSPA) which has been formed to be the voice of the Malaysian Spa industry to educate the public knowledge and professional service delivery.

However, past research shows that some gaps exist within the Spa industry that makes it unable to perform. With the presence of such undefined gaps within the industry, it makes the sector unable to expand its market scale and indeed serves as a barrier to the growth of this industry which needs to be solved immediately. Highlighting the unsolved gaps related to this industry, lack of studies has been done in identifying the motivations of tourist in visiting Spa and Wellness tourism destination especially at Kuala Lumpur which is the main city of Malaysia and in this case, it might be a solution to identify those problems related to the gaps in this industry.

For this reason, this study seeks to examine the reliability and validity of the proposed scale of measurement and how it may contribute to the factors influencing tourist motivation towards visiting spa and wellness tourism destination specifically to Kuala Lumpur destinations. The validity and reliability are the primary objectives to ensure that problems will not occur which may cause the main research project to fail. 


\section{RESEARCH METHODOLOGY}

\section{A. Instrumentation and Measurement}

The questionnaire was designed to conduct a pilot study from the domestic tourist. There are six sections developed, which is section $\mathrm{A}, \mathrm{B}, \mathrm{C}, \mathrm{D}, \mathrm{E}$ and $\mathrm{F}$ In section $\mathrm{A}$, the researcher was asked the questions related to relaxation \& relief. Section B consisted of questions related to health \& beauty. Section $C$ was asked on escape variable while section D was asked about self-development. Next, section E was asked questions related to the dependent variable, which is with tourist motivation.

Last but not lease section $\mathrm{F}$ was asked about seven demographic questions. The instruments of the study were adopted and adapted from the previous studies, for instance [1];[6]. Five-point Likert scales were employed for these items, ranging from $(1=$ very strongly disagree to $5=$ very strongly agree).

\section{B. Result of Reliability Test}

Table 1: Reliability of Instrument rule of thumb

\begin{tabular}{cc}
\hline $\begin{array}{c}\text { Alpha Coefficient Range } \\
<0.6\end{array}$ & $\begin{array}{c}\text { Strength of Association } \\
\text { Poor }\end{array}$ \\
0.6 to $<0.7$ & Moderate \\
0.7 to $<0.8$ & Good \\
0.8 to $<0.9$ & Very Good \\
$0.9>$ & Excellent
\end{tabular}

[8]

Table 2: Alpha Coefficient of internal reliability for each section of the questionnaire

\begin{tabular}{|c|c|}
\hline \multicolumn{2}{|c|}{$\begin{array}{c}\text { Factors Influencing Travel Motivation To Visiting Spa } \\
\text { And Wellness Tourism Destinations }\end{array}$} \\
\hline Section 1: Relaxa & \\
\hline Alpha Coefficient & 0.801 \\
\hline Number of items & 5 \\
\hline \multicolumn{2}{|c|}{ Section 2: Health and Beauty } \\
\hline Alpha Coefficient & 0.856 \\
\hline Number of items & 5 \\
\hline \multicolumn{2}{|l|}{ Section 3: Escape } \\
\hline Alpha Coefficient & 0.823 \\
\hline Number of items & 5 \\
\hline \multicolumn{2}{|c|}{ Section 4: Self Development } \\
\hline Alpha Coefficient & 0.769 \\
\hline Number of items & 5 \\
\hline \multicolumn{2}{|c|}{ Section 5: Travel Motivation } \\
\hline Alpha Coefficient & 0.955 \\
\hline Number of items & 3 \\
\hline \multicolumn{2}{|c|}{ Section 6: Demographic Profile } \\
\hline Number of items & 8 \\
\hline
\end{tabular}

This study has conducted the reliability and validity test before conducting the actual data collection process. To improve the reliability, there are four criteria followed by the researchers which is: (1) configuring all constructs, (2) improving measurement levels, (3) using some indicators, and (4) conducting pilot studies. Following the rule of thumb by [8] in table 1 , the value less than 0.6 is considered poor, while 0.70 is considered good and the value more than 0.8 is considered very good. The score for items below than 0.70 was deleted or filtered.

In addition, the researchers were taken the necessary care in ensuring the validity content of the scales will be used. Therefore, an academician from several Universities was asked to look at into the validity content. Table 2 showed the result obtained from the pilot study. From the data presented, it is noticeable that all the measures possess a high-reliability standard ranging from Relaxation \& Relief $(0.801)$, Health \& Beauty (0.856), Escape (0.823), Self-Development (0.769) and Travel Motivation (0.955) which show good internal consistency. An instrument with a coefficient of 0.60 and above is regarded to have an average liability [8]. Thus, the questionnaire can be considered as an official question and it can be used for conducting an actual future study.

\section{Data Distribution}

Normality test is a kind of test that is used to determine if a data set is well arranged or distributed by a normal distribution and to compute how likely it is to a random variable underlying the data set to be normally distributed. Normality of the data needs to be tested to avoid statistical errors, which create an invalid outcome. According to [3], normal data refers to when the sample is taken; the data is capable of representing the symmetrical distribution. In addition, the result obtained from this test will be used in deciding whether to use Pearson Correlation analysis, Spearman analysis or Kendall's tau-b analysis. According to [2] in his book of Principles of Statistic, he had suggested a rule of thumb mentioning that:

i. If the skewness is less than -1 or greater than +1 , therefore the distribution is highly skewed.

ii. If the skewness is between -1 and $-1 / 2$ or between $+1 / 2$ and +1 , therefore the distribution is moderately skewed.

iii. If the skewness is between $-1 / 2$ and $+1 / 2$, therefore the distribution is approximately symmetric.

\section{Data Analysis}

The data collection process was conducted at Kuala Lumpur in the weekend. A total of 150 responses were obtained to answering the pilot test questions. The data of this study were analysed using the IBM SPSS version 23 by looking at cronbach alpha values. The detail of the data values is listed in table 2 .

\section{CONCLUSION}

The main focus of this pilot study is to establish the validity and reliability of the measuring instruments purposely to measure the travel motivation factors towards visiting Spa and Wellness tourism destinations before the actual study is conducted. A pre-test was done whereby an expert's point of view has assessed the content and face validity of the questionnaire.

Furthermore, the reliability test showed that all the items

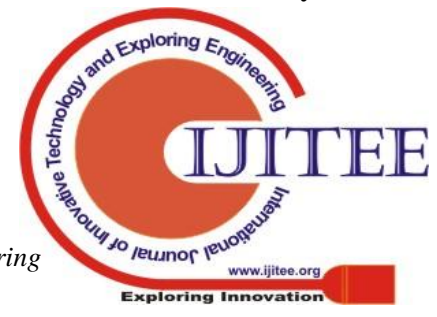


are reliable with Cronbach's Alpha greater than 0.7, which showed that there is no need for deleting any item since it considers good items. In addition, the normality test shows that the data is rationally normal, thus demonstrated the study protocol is feasible. On the whole, the questionnaire has been validated through the examination of its measures "reliability and construct" validity.

The actual study, which is expected to collect around 400 tourists, would be able to give a glimpse on tourist's motivation factors and their behavioural intentions, particularly in visiting Spa and wellness tourism destinations. The result of this study make some implications to the current knowledge of the related fields and useful for policymakers, tourism associations and practitioners to enhance the Malaysian tourism industry. At the same time, it will be able to be a benchmark for future study.

\section{REFERENCES}

1. Athena H.N Mak, K. K. (2009). Health or Self-indulgence? The Motivation And Characteristic Among Spa Goers. International Journal of Tourism Research, 185-199.

2. Bulmer, M.G. (1970). Principles of Statistics. United States: Dover Publication Inc.

3. Das, K. R., \& Imon, A. H. M. R. (2016). A brief review of tests for normality. American Journal of Theoretical and Applied Statistics, 5(1), $5-12$.

4. Global Wellness Summit. (2016). Summit Mission. Retrieved from http://www.globalwellnesssummit.com

5. Hashemi, S.M., Jusoh, J., Kiumarsi, S., \& Mohammadi, S. (2015). Influence Factors Of Spa and Wellness Tourism on Revisit Intention: The Mediating Role of International Tourist Motivation and Tourist Satisfaction. International Journal of Research, 3(7),1-11.

6. Henna Konu and Tommi Laukkanen. (2009). Roles Of Motivation Factors In Predicting The Tourist's Intention To Make Wellbeing Holidays - A Finnish Case. ANZMAC , 1-9.

7. Hyde-Smith, M. J., (2012).The Wellness Spa: Construct Definition and Performance Evaluation(Unpublished Doctoral dissertation) Auckland University of Technology.

8. Sekaran, U., Bougie, R. (2017). Research Methods for Business: A Skill Building Approach. United Kingdom: John Wiley \& Sons, Ltd, Publication.

9. Smith, M., \& Puczkó, L., (2008).Health and wellness tourism. Routledge.

\section{AUTHORS PROFILE}

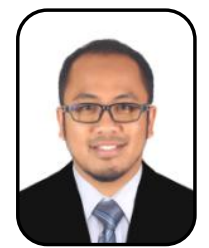

Nik Alif Amri Bin Nik Hashim is a lecturer in the Department of Tourism Management, Faculty of Hospitality, Tourism and Wellness (FHPK), Universiti Malaysia Kelantan (UMK). He holds a Bachelor Science of Tourism Management minor Hospitality and holds a Masters Degree in Tourism Management from Universiti Teknologi MARA (UiTM). He has been involved in research projects and releases many articles nationally and internationally. Among his areas of expertise are Tourism and Hospitality Management, Travel Risk Perceptions, Destination Destinations, Tourist Travelers and Intimate Adventures, Event Management in Tourism and Crisis \& Disaster Management. He is currently pursuing a Doctor of Philosophy $(\mathrm{PhD})$ in Tourism \& Hospitality at the University of Queensland, Australia.

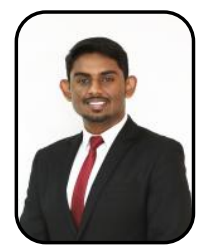

Sathish Kumar Velayuthan, tourism lecturer in the Department of Tourism Management, Faculty of Hospitality, Tourism and Wellness (FHPK), Universiti Malaysia Kelantan (UMK). His research interests are in Tourism Development, Tourism Heritage \& Culture, Tourism Technology and mobile development. He is currently pursuing a Doctor of Philosophy $(\mathrm{PhD})$ in Tourism \& Hospitality at Universiti Teknologi Malaysia, Malaysia.

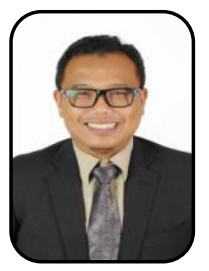

Abdullah Bin Muhamed Yusoff is a lecturer at Hospitality Department, Faculty of Hospitality, Tourism and Wellness (FHPK), Universiti Malaysia Kelantan (UMK). He holds a Master's Degree in Gastronomy from Universiti Teknologi MARA (UiTM). He has been involved in research projects and publishes many articles nationally and internationally. Among his areas of expertise are Malay Cuisine; Culinary Art Management; Restaurant \& Service Operation; Consumer Behavior and Fine Dining Restaurant He has extensive experience in the Hospitality industry and is now in the quest to develop his expertise.

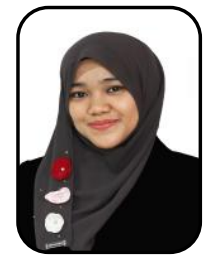

Zaimatul Binti Awang is a tourism lecturer in the Department of Tourism Management, Faculty of Hospitality, Tourism and Wellness (FHPK), Universiti Malaysia Kelantan (UMK). He holds a Bachelor Science of Tourism Management minor Hospitality and holds a Masters Degree in Tourism Management from Universiti Teknologi MARA (UiTM). Her research interests are in Tourism Management, Tourism Crisis \& Disaster Management, Tourism Heritage \& Culture and Tourist Behaviour. She is currently pursuing a Doctor of Philosophy $(\mathrm{PhD})$ in Tourism \& Hospitality at public university in Malaysia.

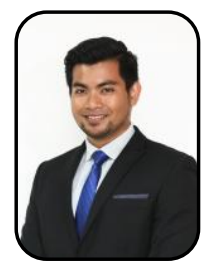

Fauzan Hafiz Muhammad Safri, tourism lecturer in the Department of Tourism Management, Faculty of Hospitality, Tourism and Wellness (FHPK), Universiti Malaysia Kelantan (UMK). His research interests are in Event Management in Tourism, Tourism Heritage \& Culture, Tourism Management, Food Tourism, Tourist Behaviour. He is currently pursuing a Doctor of Philosophy $(\mathrm{PhD})$ in Tourism \& Hospitality at public university in Malaysia 